\title{
Barriers to BIM implementation and ways forward to improve its adoption in the Nigerian AEC firms
}

\author{
Babatunde, S.O., Udeaja, C. and Adekunle, A.O (2020)
}

\begin{abstract}
Purpose -BIM has much potential to improve the effectiveness of construction works with respect to design, construction and maintenance. However, many Architecture, Engineering, and Construction (AEC) firms are still lagging in the adoption and implementation of BIM in both developing and developed countries. The purpose of this study is to assess the barriers to BIM implementation, and examine the ways forward to improve BIM adoption within the Nigerian AEC firms.

Design/methodology/approach - A comprehensive literature review and questionnaire survey were used in the study. The survey targeted four different AEC firms. These include architectural firms, facility management firms, quantity surveying firms and structural engineering firms in Lagos, Nigeria. The data obtained were analyzed using mean score, standard deviation, KruskalWallis test, and factor analysis.
\end{abstract}

Findings - The study identified 20 barriers to BIM implementation and identified 10 ways forward to improve BIM adoption in AEC firms, particularly in Nigeria. The relative importance of both the identified barriers and the ways forward were gauged. The Kruskal-Wallis tests revealed that except for one (out of 20) identified barriers, and one (out of 10) identified ways forward; there is no statistical significant difference in the perceptions of four different AEC firms. The factor analysis result grouped the 20 identified barriers into three major factors to include: weak top management support and BIM environment related issues; cost of BIM software and training issues; and incompatibility, legal, contractual, and culture related issues.

Practical implications - The significance of the study cannot be over-emphasized due to BIM relevance to construction stakeholders and researchers at large.

Originality/value - The study findings would inform the decisions of the construction stakeholders to make some policy recommendations capable of positively influencing the full BIM implementation in AEC firms.

Keywords AEC firms, BIM, barriers, construction stakeholders, construction industry, developing countries

Paper type Research paper

\section{Introduction}

The construction industry had been plagued by various problems such as fragmentized project delivery processes that are based on paper-oriented means of communication, which was prone to human errors, and omissions that usually lead to cost overrun, prolong delays, and disputes among the stakeholders in construction projects (Eastman et al., 2008). However, the AEC firms in a bit to mitigate these challenges developed many methods such as design and build method, project web sites and 3D CAD tools (Eastman et al., 2008). Although these methods enhance the 
rapid exchange of information, it has not been able to eradicate the problems associated with paper-oriented means of communication such as inability to detect parametric capability, conflicts and constructability issues among others (Abdullah and Ibrahim, 2016). Building information Modeling (BIM) was developed to provide basis for resolving the inefficiencies of the previous Computer Aided Drawing (CAD) by providing a working digital environment that incorporates all information about a building in an electronic file, and used by the various project stakeholders (Abdullah and Ibrahim, 2016). Aouad et al. (2014) described BIM as a virtual demonstration of functional features of a project. BIM is one of such inventive methods that have the potential to bring about the incessant progress and anticipated changes in the construction industry and reform the methods of its operation to accomplish enhanced cooperation among contractual parties and ascertain successful delivery of project (Azhar, 2011). BIM is currently regarded as a fast growing digital technology having the inherent attributes to improve the management of information in construction (Migilinskas et al., 2013). However, Alufohai (2012) argued that BIM adoption has not been generally embraced by AEC firms in both developed and developing countries and has experienced stunt growth due to challenges associated with BIM usage. This statement has been corroborated by Eadie et al. (2013) who asserted that there are various factors hindering the progress of BIM.

In Nigeria, the construction industry is more fragmentized that various construction professionals usually generate project information and manage them individually (Onungwa et al., 2017). Hamma-adama et al. (2017) and Kori (2015) claimed that architectural, mechanical, electrical and plumbing designs are still prepared using 2D CAD platform with only few (especially Architects) using 3D CAD platform basically for visualization or demonstration. This is affirmed by Hamma-adama et al (2017) that the current status of BIM uptake in Nigeria is the predominant usage of 2D and 3D. Smith and Tardif (2009) argued that if BIM is used merely for presentation, detection of clashes and visualization, the numerous inherent capabilities it possesses may remain un-tapped. It can be deduced that these restricted uses of BIM reflect deficiency of BIM knowledge within the Nigerian construction industry context (Ugochukwu et al., 2015). Also, Ibrahim and Bishir (2012) asserted that BIM adoptions and usage in most developed nations are on the increase, however, the extent of BIM adoption particularly in developing countries is best describe as stagnant.

Relevant previous BIM studies in Nigeria were specific to a particular firm. For example, studies on BIM adoption and awareness in architectural firms (see Ibem et al., 2018; Kori and Makarf, 2018; Kori et al., 2019). BIM studies in facility management firms (see Ikediashi and Joseph, 2016; Olapade and Ekemode, 2018) among others. In addition, studies that examined BIM adoption, awareness, and implementation among Architecture, Engineering, and Construction (AEC) firms (see Olugboyega and Aina, 2016; Onungwa et al., 2017; Ganiyu et al., 2018; Olabode and Umeh, 2018). Few studies assessed BIM training gaps among construction professionals (see Oyewole and Dada, 2018). Few other studies examined BIM maturity level among AEC firms comprised architectural firms, facility management firms, quantity surveying firms, and structural engineering firms (see Babatunde et al., 2019). It is evident from the aforementioned previous studies that they are not only specific to a particular firm, but they also focused on BIM awareness and utilization in Nigeria. It is therefore expedient to carry out an explicit study that comprises a comparative analysis with particular emphasis on barriers to BIM implementation in each AEC firm with a view to having a balanced knowledge of BIM 
implementation among AEC firms in Nigeria. The quest to fill this knowledge gap is what birthed the need for this study. It is believed this study would provide a better insight of Nigeria BIM environment that is a true reflection of developing countries at large. This study would further inform the decisions of the construction stakeholders to make some policy recommendations capable of positively influencing the full BIM implementation in AEC firms.

\section{Literature review}

Current state of BIM implementation in the Nigerian construction industry

Onungwa et al. (2017) asserted that there is low level of awareness and technical know-how of BIM in Nigeria. This can be linked to lack of adequate BIM training and inadequate exposure to BIM concept (Abubakar et al., 2013; Onungwa et al, 2017). In Nigeria, both medium and largesized firms involved in construction activities are predominantly at the foremost in the implementation of BIM (Kori, 2015). However, firms that are relatively small in size rarely use BIM in their practices. Generally, the construction industry in Nigeria is fragmentized, this implies that various construction professionals usually generate project information and manage them individually. Hamma-adama et al. (2017a) and Kori (2015) found that architectural, mechanical, electrical and plumbing designs are still prepared using 2D CAD platform with only few, especially architects using 3D CAD platform basically for visualization or demonstration. Smith and Tardif (2009) argued that if BIM is used merely for presentation, detection of clashes and visualization, the numerous inherent capabilities it possesses may remain un-tapped. Similarly, these restricted uses of BIM reflect deficiency of BIM knowledge in the Nigerian construction industry (Ugochukwu et al., 2015). Hamma-adama et al (2017b) opined that change of behavior from the traditional method of procurement is necessary, but change of behavior to successfully implement BIM is often difficult as it requires a complete transition of work processes.

Although BIM implementation in most developed nations are on the increase, however, the extent of BIM implementation in most developing nations such as Nigeria is best described as stagnant (Ibrahim and Bishir, 2012). This is affirmed by Hamma-adama et al. (2017a) that the current status of BIM uptake in Nigeria is the predominant usage of 2D and 3D. However, a more comprehensive and exhaustive examination of the levels of development of BIM in the Nigerian construction industry by Olugboyega and Aina (2018) showed that both two dimensional and various variants of three dimensional building information modeling such as 3D architectural model, 3D architectural and structural model and 3D architectural and building services model were the most widely used in Nigeria. It is quite unfortunate there are no government policies in place to encourage BIM implementation in Nigeria, which is a true reflection of developing countries as whole. Studies have shown that currently BIM implementation in Nigeria is been requested mostly by private building owners and corporate organizations while the governments at all levels (i.e. federal, state and local) are not showing much interest in the implementation of BIM for the delivery of public projects.

Comparative review of BIM adoption: global context

The usage of BIM has transformed the construction industry. Increase in profit via cost savings and timely delivery of projects are some of the numerous advantages of using BIM for 
construction works. United Kingdom BIM Strategy Report (2012); Wong et al.(2009) and BuildSmart (2012) reported that several governments of developed countries including the United Kingdom, United States of America, Australia among others have set up strategies for the implementation of BIM in their construction works which has led to rapid BIM adoption. For instance, Efficiency and Reform Group (2011) established a road map for the adoption of BIM in the United Kingdom to implement BIM and achieve efficacies. In Australia, government had proposed compulsory usage of BIM on public financed projects as from the first phase of year 2016 (BuildSmart, 2012). A survey conducted by Kjartansdottir (2011) on the adoption of BIM in Iceland showed that not less than forty percent of construction professionals use BIM in their practices, especially architects and engineers.

BIPS (2012) reported that Denmark and Norway are among the countries that have developed proficiency in the implementation of BIM, having mandated the usage of BIM on public projects since 2007. The adoption of BIM in the United States of America showed a significant increase in BIM usage from twenty-eight to forty-eight percent which is far more than the percent in other developed countries (McGraw-Hill, 2009; Eadie et al., 2014). McGraw-Hill (2008) found out that sixty-two percent of the respondents showed willingness to use BIM on not less than thirty percent of their project in 2009; eighty-two percent of BIM users admit increase in output of work done and forty-four percent are currently using BIM to ascertain "Return On Investment". According to McGraw-Hill (2009) most BIM users obtained numerous advantages from using it and the percent of BIM usage to find out return on investment has risen to sixty-three percent. The implementation of BIM is fast-growing as building owners and government agencies were prompted to adopt BIM, based on its benefits such as timeliness, reasonability of project cost and high quality among others. It is therefore evident that most nations of the world recognized the inherent capability of such innovative processes for reformation of practices in the construction industry. Lee et al. (2014) stated that BIM processes were made compulsory by the United States of America and United Kingdom government agencies to assist construction professionals' practices in the industry and to satisfy and surpass clients' needs and expectations; they further stated that since 2006, the United States of America general services administration incorporated programme such as spatial arrangement of BIM as one of the least prerequisite for final approval of proposals.

As a result, the United States of America has been recognized as a leading country in the BIM implementation, subsequently the adoption level in North America sky-rocked from twenty-eight percent to seventy-one percent within the period of 2007 and 2012, and similar experiences were reported in the United Kingdom with contractors and architects adoption level amounting to seventy-four and seventy percent respectively (McGraw-Hill, 2014). According to Matarneh and Hamed (2017), the government of the United Kingdom has a foresight of becoming the frontier of BIM in Europe; they further stated that despite the increase in the usage of BIM world-wide, the experience in relation to BIM differs from one construction to another. Singh (2017) investigated BIM adoption in developed nations and found that in Finland, BIM implementation commenced since in 2002 and by 2007, it was established that all design must be IFC certified. In Norway, BIM and IFC data format had been used since 2010; In Denmark, government had mandated the usage of BIM coupled with research and development works in relation to BIM are currently conducted at the organizational and institutional level; In Sweden, BIM is widely adopted without compulsion from the government but are only deficient in BIM research publications when compared to the United States of America; In Singapore, government 
encouraged the implementation of BIM by making the usage of BIM mandatory for large project and provision of adequate fund for the training and procurement of BIM software and hardware; In France, the government officials in a bit to fully adopt BIM, resolved in 2014 to use BIM in the development of not less than five hundred houses by 2017; South Korean being one of the frontiers of BIM adopters had been making tremendous efforts since 2010 to cause an increment in the number of BIM oriented projects by the provision of funds for the establishment of BIMoriented building design standards and mandatory use of BIM on all government projects over fifty million dollars since 2016 .

China Construction Industry (2013) reported that BIM adoption level in China is very low; this is however attributed to government not acting as "role model" in the adoption of BIM. In Hong Kong, Lu et al. (2018) found that BIM maturities of construction-related organizations in Hong Kong vary, with more than half ranging from Stage 0 to 1; and this was attributed to the different developments of their BIM processes and protocols. However, the BIM implementation in Africa differs from one country to another. For instance, in South Africa construction professionals are still confronted with barriers in the adoption of BIM (Succar, 2009). In Nigeria, the BIM awareness is relatively high compared to its usage among AEC firms (Ogwueleka, 2015). This is corroborated by Ugochukwu et al. (2015) that not less than sixty-seven percent of construction professionals are aware of BIM in Nigeria but very few have implemented BIM in their practices. It is surprising that BIM has been rarely used for construction works in Nigeria (Alufohai, 2012). This is affirmed by Olugbenga et al. (2016) that currently BIM usage in Nigeria is been requested mostly by building owners and developers but the government is not showing any interest in the implementation of BIM for the delivery of public projects. Against this backdrop, this study becomes necessary to critically examine the militating factors to BIM full implementation and the ways forward to improving its adoption among AEC firms in Nigeria.

\section{Barriers to BIM implementation among AEC firms}

BIM implementations have not been generally embraced by many AEC firms, particularly in developing countries. Thus, some selected barriers to BIM implementation as identified by previous studies are briefly discussed as follows:

The structure of the construction industry

BIM implementation usually involves a complete change in practice with respect to procedures and principles (Ezeokoli et al., 2016). Kori and Arto (2015) opined that the attitude of construction professionals to change from an existing process to a new one poses more problems than acquiring the skills. This is because traditional method of procurement has been used long enough that it is extremely difficult to embrace a new process. Zahrizan et al. (2013) argued that managers at the corporate level had been identified as a key factor that brings about incessant incorporation of changes to innovation. However, when these managers are duly informed, incorporating changes in the firms become easy, thus for any firm to change from the conventional means of procurement requires taking deliberate steps to embrace the implementation of BIM. 
Low level of BIM technical know-how and awareness

Zahrizan et al (2013) argued that the obscurity of BIM in the construction industry can be traced to the relatively inadequate level of awareness and technical know-how of BIM among construction professionals. Liu et al. (2015) recognized inadequacy of appropriate skills and technical know-how in the usage of BIM as one of the major barriers to the adoption of BIM in their individual nations. Saxon (2013) noted that currently BIM is often utilized and is experiencing instantaneous growth in most developed nations. For example, RICS (2014) reported that BIM was applied on more than seventy percent and thirty-six percent of the construction works in the United States of America and Europe respectively, but this is in contrast to what is prevalent in Africa. Although the awareness level is increasing progressively, the degree to which BIM is been implemented on construction works is seemingly low. For instance, Hosseini et al. (2015) found out that about twenty-nine percent of the construction firms in Iran adopted BIM in their practices and about fifty-six percent have not heard of BIM. Saxon (2013) claimed that only fewer number of BIM applications are recorded in developing countries because construction participants are yet to develop capability to use BIM.

Inaccessibility to suitable technology and framework

Accessibility to BIM technology and framework had a significant effect on BIM implementation. For instance, Zahrizan et al (2013) asserted that even if firms embrace changes from an existing process to a new one without accessibility to suitable technology such changes will be short leave. They further identified that the inability to gain access to technology and framework serve as a major barrier to the implementation of BIM in most developing nations. Obiegbu and Ezeokoli (2014) argued that BIM technologies available for sale are costly to procure and set-up. Thus, new BIM users might incur excessive expenses which might even affect their profit at the early stage (Hergunsel, 2011).

\section{Individual perception/ point of view}

Zahrizan et al (2013) claimed that most construction professionals in developing nations are somewhat afraid of the implementation of BIM in their practices. Simply because it requires a transition from the conventional processes prevalent in the construction industry, thus reluctance to embrace improved but new working environment becomes one of the foremost barriers impending the usage of BIM.

Absence of appropriate BIM guidelines

It is a mere illusion to desire the attainment of purposeful changes without procedure and regulation in place to implement it (Ezeokoli et al., 2016). Inadequate support from the government for BIM implementation and general regulation has been recognized to have a negative impact on the usage of BIM, thus each BIM user adopt their own principle without directive from the vendor which will inevitably result to differences in the detail level in relation to various firm (Zahrizan et al., 2013; Abubakar et al., 2014).

\section{Industry/working environment}

With the varieties of software packages at the disposal of designers (Architects and engineers) to generate designs that are better than the conventional or traditional practice, it is evident that the incorporation of data in the electronic model of buildings has successfully eradicated many possible disputes but has not been able to incorporate the rudiment of business procedure. In the absence of such procedures, data and associated tools will not develop appropriately due to its inability to indicate progress of work being done and collaboration of data (Bernstein and 
Pittman, 2014). In addition, Hosseini et al. (2015) identified market structure, working environment, inadequate support from the government and absence of appropriate policy as barriers to the implementation of BIM.

Initial BIM huge capital outlays

The implementation of BIM for "first timers" involves initial huge capital outlays which include procurement of BIM computer hardware and software packages, cost of staff training among others (Hong Kong Construction Industry Council, 2013; Memon et al., 2014). Also, Young et al. (2008) asserted that the capital required for the procurement of BIM software and upgrading of computer hardware is quite enormous. For example, Gardezi et al. (2014) identified barriers to BIM implementation in Malaysia to include cost of BIM generally, market condition and firms' behaviours. Memon et al (2014) argued that outright transition from conventional processes to new processes, such as BIM, has huge cost implications and as such business owners are reluctant to implement it except they are able to associate it with long-term gain in relation to their respective firms as well as a substantial reduction in cost of training from vendors.

In summary, the identified barriers from previous studies are presented in Table I as follows:

>>>>>>>>Insert Table I $>>>>>>>>>$

It can be seen from Table I that several studies have been conducted, particularly in developed countries on barriers to BIM implementation in the construction industry, but limited studies have been conducted in Nigeria. For instance, few of these studies conducted in Nigeria include Abubakar et al. (2014) who examined the perceptions of contractors on the factors influencing BIM in Nigeria and the study failed to evaluate the BIM barriers from the perceptions of consulting firms. Babatunde and Ekundayo (2019) evaluated the barriers to incorporation of BIM into quantity surveying education from academia and students' perspectives; hence the study (Babatunde and Ekundayo, 2019) failed to examine the phenomenon from industry stakeholders' perspectives. It is obvious that studies that examine the barriers to BIM implementation among consulting firms in the Nigerian construction industry through quantitative approach are limited. It is against this backdrop that four different AEC firms comprised architectural firms, facility management firms, quantity surveying firms and structural engineering firms that already adopted BIM for their practices are considered as respondents in this study.

\section{Ways forward to improve BIM implementation among AEC firms}

The implementation of BIM in AEC firms has attained a level of maturity most especially in developed countries like the United States of America and UK. It has received several measures to its improvement among professional firms which its adherence has been put to place in several developed countries. For instance, Poole (2014) identified collaboration, training and promotion as the way forward for BIM implementation in Hong Kong. BuildSmart (2013) reported the BIM roadmap in Singapore to include public sector takes the lead, regulatory approval, remove impediments, build BIM capability and capacity and incentivize early BIM adopters. Ezeokoli et al (2016) identified measures to improving BIM usage in the order of importance to include education and training programme, incorporation of BIM to academic curriculum, enactment of BIM guideline and regulation, provision of appropriate technology and infrastructure, BIM 
should be made compulsory for all procurement processes and contracts and finally, setting up BIM council. Alufohai (2012) suggested that software vendors and relevant training institutes should embark on intensive awareness of BIM, BIM tools and associated benefits. The author further proffered that the relevant professional bodies both local and international should keep their member up-to-date by organizing trainings, workshops, and seminars on BIM implementation. Isa (2015) identified strategies for overcoming BIM barriers to include improve BIM awareness and understanding, outsourcing BIM experts, provision of training by employers, provision of BIM education at higher institutions, government legislation supporting the use of BIM, clients demand for BIM, government support, developing BIM guidelines and improved data exchange standards. It is obvious that several measures to improve BIM implementation have been identified, but none of these measures have been investigated, particularly through an empirical approach in Nigeria. Therefore, it becomes imperative to empirically assess the measures to improve the implementation of BIM among AEC firms in Nigeria. It is against this backdrop that four different AEC firms were considered in this study. These include architectural firms, facility management firms, quantity surveying firms and structural engineering firms in Lagos, Nigeria.

\section{Research methodology}

The study utilized literature review and questionnaire survey. For instance, an extensive literature was conducted to identify various barriers influencing BIM full implementation in AEC firms and various ways forward to improving BIM adoption among AEC firms in a wider context. The barriers were identified from earlier studies (see Saxon, 2013; Zahrizan et al., 2013; Abubakar et al., 2014; Gardezi et al., 2014; Memon et al., 2014; Liu et al., 2015; Hosseini et al., 2015) among others. Similarly, the ways forward to improving BIM adoption were as well identified from important literature (see Alufohai, 2012; BuildSmart, 2013; Poole, 2014; Isa, 2015). The outcomes of both extensive review produced 20 barriers to BIM implementation and 10 ways forward to improving BIM adoption in AEC firms. Thereafter, both the 20 identified barriers and 10 identified ways forward were utilized in designing the questionnaire survey. A questionnaire survey was used to capture wider perceptions of the respondents. This approach is widely supported by earlier studies, particularly in construction economics and management studies. This is corroborated by Cheung (2009) that a questionnaire survey is an efficient approach to collect data in a quantitative research. Notable earlier researchers in BIM studies have largely adopted questionnaire survey (see Abanda et al., 2015; Amuda-Yusuf, 2018; Babatunde et al., 2018) among others.

The target population for this study comprised four different AEC firms to include: architectural firms; facility management firms; quantity surveying firms; and structural engineering firms in Lagos, Nigeria. The choice of the study area is due to the fact that a large percentage of AEC firms are situated in Lagos state. Thus, the study area is adjudged appropriate to undertake a survey and obtain the required data (Babatunde, 2015). The total lists of the aforementioned four selected firms were obtained from their respective professional bodies in the study area. The lists include only firms that paid their dues to their respective professional bodies to date as follows: 287 architectural firms; 57 quantity surveying firms; 78 structural engineering firms; and 18 facility management firms. For objectivity, 50 architectural firms, 50 quantity surveying firms, 50 structural engineering firms were purposively selected. Except for facility management firms, 
the entire 18 firms were selected due to their small population. This is resulting into a total of 168 firms as a sample size. Hence, a total of 168 questionnaires were self-distributed, which 107 questionnaires, representing $63.69 \%$ response rate were received and suitable for the analysis.

Moreover, the questionnaire designed for this study was structured and multiple-choice type. For instance, the questionnaire was divided into two broad sections. Section 'A' comprised the background information of the respondents; this includes the AEC firm's category, highest academic qualifications of the respondents, years of work experience, and designation of the respondents. Section B was designed in relation to the barriers to BIM implementation and ways forward to improve BIM adoption among AEC firms in the study area. For example, the questions on the barriers to BIM implementation were asked on a five-point Likert scale rating with 5 being the highest of the rating, where 5-Very high, 4- High, 3-Moderate, 2-low, and 1very low. Similarly, the questions on the ways forward to improve BIM adoption were asked on a five-point Likert scale rating, where 5-Very high relevance, 4-High relevance, 3-Moderate relevance, 2- low relevance, and 1-very low relevance. Moreover, reliability tests using the Statistical Package for Social Science (SPSS V 21.0) was conducted on the research instrument in this study. Thus, the questionnaire for this study was subjected to Cronbach's alpha test using SPSS. The result indicated the reliability coefficient values of Cronbach's alpha for three extracted factors obtained from the factor analysis. For instance, three factors for the BIM barriers extracted from the factor analysis with their Cronbach's Alpha are as follows: Factor 1: Weak top management support and BIM environment related issues; Factor 2: Cost of BIM software and training; and Factor 3: Incompatibility, legal, contractual and culture related issues with their values of Cronbach's alpha $0.934,0.933$ and 0.934 respectively. This approach was supported by earlier studies (see Tuuli and Rowlinson, 2009). These values signified that the questionnaire, including the Likert scale used was significantly reliable and indicate evidence of internal consistency. This was supported by several earlier researchers that Cronbach's alpha value of greater than 0.6 is reliable and acceptable (Pallant, 2007).

The data obtained were analyzed using mean score, standard deviation, Kruskal-Wallis test, and factor analysis. The mean score was employed for the ranking of identified 20 barriers to BIM implementation and 10 identified ways forward to improving the BIM adoption in AEC firms. Kruskal-Wallis test was undertaken to ascertain if there is a statistical significant difference in the perceptions of four different groups (i.e. architectural firms, facility management firms, quantity surveying firms, and structural engineering firms) in the aforementioned mean ranking. Using Kruskal-Wallis test was widely encouraged by earlier researchers when the samples are not less than three different groups with ordinal data (Zikmund, 2003; Fellows and Liu, 2008). In addition, factor analysis was carried out to identify a small number of factor categorizations that could be used to show relationships among a set of numerous inter-related variables (Pallant, 2010; Hair et al., 2010). Thus, the factor analysis was undertaken on the 20 identified barriers to BIM implementation with a view to determining the underpinning interactions or grouping that might exist between the identified barriers. It is worthy to mention that factor analysis was not conducted on the ways to improve BIM adoption because there are fewer identified variables, precisely 10 variables. Thus, as a first step in conducting factor analysis, the suitability of the survey data collected was examined using Kaiser-Meyer-Olkin (KMO) test and Barlett's test of specificity (Pallant, 2010). Hence, the result of KMO value of 0.906; implied that the data obtained were confirmed satisfactory for accurate completion of factor analysis (see Pallant, 
2010; Hair et al., 2010). Similarly, Barlett's test of specificity value of 0.000; indicated that the correlation is strong enough to be accurate and suitable for conducting factor analysis. This was supported by the assertion of earlier researchers that Barlett's test of Sphericity value should be significant $(p<0.05)$ for the factor analysis to be considered appropriate (Field, 2005; Pallant, 2010; Hair et al., 2010). After the data obtained were confirmed satisfactory, the factor analysis was undertaken on the identified 20 barriers to BIM implementation in AEC firms.

\section{Results and discussion}

The respondents' background information

Table II reveals the distribution of questionnaires to the respondents comprised architectural firms, facility management firms, quantity surveying firms, and structural engineering firms. As indicated in Table II, both the architectural firms and quantity surveying firms have higher rate of returns compared to other AEC firms in the category despite their tight schedules. This may be attributed to their interests in BIM research and their full awareness of BIM relevance to their professions.

>>>>>>>> Insert Table $\mathrm{II}>>>>>>>>>$

Table III indicates the respondents' background information in each category of the firm. It shows that majority of the respondents have MSc (Masters Degree) with 60.7 per cent, followed by BSc (Bachelor's degree) with 25.2 per cent (see Table III). The years of work experience of the respondents showed that majority of the respondents have above 10 years work experience in their respective firms. In addition, the position of the respondents in their various firms indicated that 47.7 per cent of the respondents are managing director /chief executive officer, 35.5 per cent are senior staff, and 14.0 per cent are junior staff (see Table III). It is evident that the respondents have adequate academic background, appropriate knowledge and experience to provide adequate information.

\section{>>>>>>>>Insert Table III >>>>>>>>>}

Ranking of barriers to BIM implementation in AEC firms

Table IV indicates the survey response from four selected AEC firms comprised architectural firms, facility management firms, quantity surveying firms, and structural engineering firms. As indicated in Table IV, the results of the ranking of the 20 identified barriers to BIM implementation based on each AEC firm category are as follows:

Architectural firms: The top six ranked barriers to BIM implementation from respondents in architectural firms are: low level of BIM technical know-how and awareness; cost of BIM software; inaccessibility to suitable technology and framework; initial BIM huge capital outlays; lack of senior management support; and absence of appropriate BIM guidelines with their respective mean values of $4.27,4.13,4.08,4.07,4.04$ and 4.02 , respectively.

Facility management firms: The top six ranked barriers to BIM implementation from respondents in facility management firms include: absence of appropriate BIM guidelines; low level of BIM technical know-how and awareness; frequent power failure; lack of senior management support; 
lack of support from policy makers; and initial BIM huge capital outlays with mean values of $4.03,3.97,3.90,3.88,3.88$, and 3.81, respectively.

Quantity surveying firms: The top six ranked from quantity surveying firms are: low level of BIM technical know-how and awareness; cost of software; initial BIM huge capital outlays; lack of enabling environment; inaccessibility to suitable technology and framework; and cost of training with mean values of $4.52,4.49,4.36,4.18,4.12$, and 4.05 , respectively.

Structural engineering firms: The top six ranked from structural engineering firms include: inaccessibility to suitable technology and framework; lack of vision of BIM benefits; lack of enabling environment; low level of BIM technical know-how and awareness; lack of support from policy makers; and lack of senior management support with mean values of 4.20, 4.16, $4.10,4.04,4.02$, and 4.00, respectively.

>>>>>>> Insert Table IV $>>>>>>>>>$

In addition, the ranking of total mean score values of the top six ranked barriers to BIM implementation in AEC firms are: low level of BIM technical know-how and awareness; inaccessibility to suitable technology and framework; initial BIM huge capital outlays; absence of appropriate BIM guidelines; lack of senior management support; and lack of enabling environment with their total mean score values of 4.20,4.03, 4.03, 4.02, 3.99, and 3.94 respectively. These findings confirm the existing literature. For instance, Zahrizan et al. (2013) asserted that the obscurity of BIM in the construction industry can be traced to the relatively inadequate level of awareness and technical know-how of BIM among AEC firms. Ezeokoli et al. (2016) found that that accessibility to BIM technology and framework had a significant effect on BIM adoption. In addition, Zahrizan et al. (2013) argued that even if firms embrace changes from an existing process to a new one without accessibility to suitable technology such changes will be short-lived. They further identified that the inability to gain access to technology and framework serve as a barrier to the adoption of BIM in most developing nations. Memon et al. (2014) found out that the usage of BIM for "first timers" involves initial huge capital outlays, which include procurement of BIM computer hardware and software packages, cost of staff training among others. On the other hand, the three BIM barriers that were ranked least are other competing initiatives, staff resistance and legal and contractual constraints with their overall mean values of $3.54,3.47$, and 3.28 respectively (see Table IV). These aforementioned three BIM barriers were least ranked, but considering their mean values greater than 3.00 shows that they are important barriers to BIM implementation in AEC firms. Moreover, the analyses of the total mean score values for the identified 20 barriers to BIM implementation ranges from 3.28 to 4.20 (see Table IV). This indicated that all the respondents considered these 20 identified barriers to BIM implementation as serious barriers in the Nigerian AEC firms. This assertion was supported by earlier researchers that based on the five-point Likert rating scale, an attribute was considered important if it had a mean value of 3.0 or more (Badu et al., 2012; Babatunde and Perera, 2017). Therefore, it can be deduced that there are more barriers to BIM implementation in the Nigerian AEC firms, which is a true reflection of developing countries at large. These study findings would be useful for construction stakeholders in planning towards BIM implementation in the construction industry, particularly in developing countries. 
In addition, the Kruskal-Wallis test was conducted to ascertain if there is a statistical significant difference in the perceptions of four different groups (i.e. architectural firms, facility management firms, quantity surveying firms, and structural engineering firms) in the ranking of 20 identified barriers to BIM implementation. Thus, the results of Kruskal-Wallis test showed that except one (out of 20) identified barriers to BIM implementation; there is no statistical significant difference in the perceptions of the four respondents groups. This signified that there is strong agreement among the four groups of respondents on the ranking. It is evident that the respondents have a good understanding of barriers to BIM implementation in AEC firms within the Nigerian context.

Ranking of the ways forward to improve BIM adoption in AEC firms

Table $\mathrm{V}$ indicates the ranking of the 10 identified ways forward to improve BIM adoption in AEC firms. Based on each AEC firm category, the findings are as follows:

Architectural firms: The top five ranked from the respondents in architectural firms include: incorporation of BIM to academic curriculum; improve BIM awareness and understanding; reduction in cost of implementing BIM; provision of training by employers; and provision of appropriate technology and infrastructure with their mean values of 4.71, 4.64, 4.47, 4.34, and 4.32 respectively.

Facility management firms: The top five ranked from facility management firms are: improve BIM awareness and understanding; incorporation of BIM to academic curriculum; outsourcing of BIM experts; provision of training by employers; and developing BIM guidelines with their respective mean values of $4.47,4.39,4.35,4.35$, and 4.35 respectively.

Quantity surveying firms: The top five ranked from quantity surveying firms include: provision of training by employers; incorporation of BIM to academic curriculum; improve BIM awareness and understanding; reduction in cost of implementing BIM; and government legislation supporting the use of BIM with the mean values of 4.78, 4.73, 4.72, 4.64, and 4.55 respectively.

Structural engineering firms: The top five ranked from structural engineering firms are: incorporation of BIM to academic curriculum; provision of training by employers; improve BIM awareness and understanding; reduction in cost of implementing BIM; outsourcing of BIM experts; and government legislation supporting the use of BIM with their respective mean values of $4.72,4.48,4.41,4.31$, and 4.29 respectively.

\section{>>>>>>>> Insert Table $V>>>>>>>>>$}

Similarly, the overall ranking of the 10 identified ways forward to improve BIM adoption in AEC firms indicated that the overall mean values range from 3.97 to 4.64; this implied that all the 10 identified ways forward are considered important. In addition, the overall top five ranked ways forward to improve BIM adoption in AEC firms are: incorporation of BIM to academic curriculum; improve BIM awareness and understanding; provision of training by employers; reduction in cost of implementing BIM; and developing BIM guidelines with their total mean score values of $4.64,4.56,4.49,4.32$, and 4.31 respectively. These study findings confirm the 
existing literature. For instance, Poole (2014) identified collaboration, training and promotion as the ways forward for BIM implementation in Hong Kong. Ezeokoli et al, (2016) claimed that BIM should be made compulsory for all procurement processes and contracts, and setting up BIM council. In addition, the results of Kruskal-Wallis test revealed that except one (out of 10) identified ways forward to improve BIM adoption; there is no statistical significant difference in the perceptions of the four respondents groups.

\section{Factor analysis on the barriers to BIM implementation in AEC firms}

The factor analysis was undertaken on the identified 20 barriers to BIM implementation in AEC firms. However, factor analysis was not conducted on the ways to improve BIM adoption because there are fewer identified variables, precisely 10 variables. Thus, as shown in Table VI, the data obtained were confirmed satisfactory with Kaiser-Meyer-Olkin (KMO) value of 0.906 and Barlett's test of specificity value of 0.000 (see Pallant, 2010; Hair et al., 2010). Notable earlier researchers in BIM studies supported this approach (see Memon et al., 2014; Ozorhon et al., 2016; Oduyemi et al., 2017; Amuda-Yusuf, 2018) among others.

>>>>>>>> Insert Table $V I>>>>>>>>>$

In this study principal component analysis (PCA), eigenvalue, and the scree plot were used as decision criteria (see Pallant, 2010; K'Akumu et al., 2013). This study adhered to the rule, as shown Table VII, that only three factors have eigenvalue greater than 1.0 were retained. In addition, as indicated in Table VII, since both Cronbach's alpha test and factor loading for each identified BIM barrier exceeded the threshold of 0.70 and 0.40 respectively, they were accepted with other scales being valid and reliable for this study (see Kline, 2002; Pallant, 2007, 2010; Brown, 2009). As shown in Table VII, as supported by Tuuli and Rowlinson (2009), the values

of Cronbach's alpha for each of the three factors of BIM barriers extracted from the factor analysis are $0.934,0.933$ and 0.934 respectively.

>>>>>>>> Insert Table VII $>>>>>>>>>$

These three factors were further confirmed through scree plot as recommended by earlier researchers (see Pallant, 2010).

>>>>>>>> Insert Figure $I>>>>>>>>>$

Table VII shows the extracted three factors with the total variance explained of 64.638 per cent. The three main factors extracted (see Table VII) are interpreted as follows:

Factor 1: Weak top management support and BIM environment related issues

Factor 2: Cost of BIM software and training

Factor 3: Incompatibility, legal, contractual and culture related issues

Factor1: Weak top management support and BIM environment related issues: This factor amounts to 22.285 per cent (see Table VII) of the total variance of barriers to BIM 
implementation in AEC firms. This factor has seven main items as follows: lack of senior management support; level of BIM technical know-how and awareness; inaccessibility to suitable technology and framework; lack of enabling environment; individual perception / point of view; absence of appropriate BIM guidelines; and competing initiatives respectively. These seven items have high factor loadings: $0.805,0.792,0.753,0.724,0.654,0.644$, and 0.617 , respectively (see Table VII). This study finding confirmed the assertion of Enegbuma et al. (2014); Liu et al. (2015) and Akerele and Etiene (2016) that inadequacy of appropriate skills and technical know-how in the usage of BIM is one of the major barriers to the adoption of BIM in their individual nations, among others. Thus, this study recommends that firms' top managers and decision makers should encourage the usage of BIM in their day-to-day activities and provide BIM-related workshops and seminars for their staff to acquire appropriate BIM skills and technical know-how.

Factor 2: Cost of BIM software and training: This factor amounts to 21.689 per cent (see Table VII). The five items of cost of BIM software and training as a factor include: cost of software; cost of training; initial BIM huge capital outlays; lack of supply chain buy-in; and lack of demand by clients. The factor loadings for the items are: $0.822,0.796,0.700,0.637$, and 0.636 respectively. These findings indicate that the huge financial implication of procuring BIM software and associated training of staff required are considered as a major barrier to BIM adoption and implementation in AEC firms, it is on this premise that this study recommends that the cost of BIM software and training of staff should be subsidize by the government and other approved authorities.

Factor 3: Incompatibility, legal, contractual and culture related issues: This factor has 20.663 per cent (see Table VII) of the total variance of barriers to BIM implementation in AEC firms. The items of this factor are: incompatibility and interoperability problems; legal and contractual constraints; lack of support from policy makers; staff resistance; scale of culture change required, frequent power failure; and poor internet connectivity. The factor loadings for these items include: $0.792,0.743,0.742,0.672,0.668,0.597$, and 0.586 respectively. This study finding confirmed the assertion of Abdullah et al. (2016) that legal and contractual constraints are barriers to BIM implementation. Autodesk (2011) also reported that computability of digital information and meaningful data interoperability are barriers to BIM implementation. Against this backdrop this study recommends that compatible and interoperable compliant BIM software should be develop by construction program developers and the government should make suitable construction related policies with a view to eradicating legal and contractual constraints that plagues BIM adoption in the construction industry at large.

\section{Conclusions}

BIM has much potential to improve the effectiveness of construction works with respect to design, construction and maintenance. Even though there are various factors hindering the progress of BIM implementation in AEC firms. Hence, this study assessed the barriers to BIM implementation and way forward to improve its adoption in AEC firms. The study identified 20 barriers to BIM implementation and identified 10 ways forward to improve BIM adoption in AEC firms. The relative importance of both the identified barriers and the ways forward were gauged from four different AEC firms comprised architectural firms, facility management firms, quantity surveying firms, and structural engineering firms in Nigeria. The analysis of the total 
mean score values for the identified 20 barriers to BIM implementation ranges from 3.28 to 4.20 . This indicated that all the respondents considered these 20 identified barriers to BIM implementation as serious barriers in the Nigerian AEC firms. Therefore, this study concludes that there are more barriers to BIM implementation in the Nigerian AEC firms, which is a true reflection of developing countries at large. In addition, the study revealed the overall top six ranked barriers to BIM implementation in AEC firms as follows: low level of BIM technical know-how and awareness; inaccessibility to suitable technology and framework; initial BIM huge capital outlays; absence of appropriate BIM guidelines; lack of senior management support; and lack of enabling environment. Similarly, the overall mean values of the 10 identified ways forward to improve BIM adoption in AEC firms indicated total mean values ranging from 3.97 to 4.64; this implied that all the 10 identified ways forward are important. In addition, the overall top five ranked ways forward to improve BIM adoption in AEC firms are: incorporation of BIM to academic curriculum; improve BIM awareness and understanding; provision of training by employers; reduction in cost of implementing BIM; and developing BIM guidelines. The study further revealed the Kruskal-Wallis test, which indicated that except for one (out of 20) identified barriers, and one (out of 10) identified ways forward; there is no statistical significant difference in the perceptions of respondents from four different AEC firms. This implied that there is high degree of agreement among the four groups of respondents. This finding is not surprising because the respondents are fully aware and have a common understanding on the barriers to BIM implementation and possible ways forward to improving BIM adoption in AEC firms. In addition, the study showed the result of factor analysis that grouped the 20 identified barriers into three main factors to include: weak top management support and BIM environment related issues; cost of BIM software and training; and incompatibility, legal, contractual, and culture related issues. Based on these findings, the study recommends as follows:

- massive awareness of BIM by professional bodies, government agencies, and nongovernmental organizations both locally and internationally;

- professional bodies should continue organizing BIM-related workshops and seminars for their members to further acquire appropriate BIM skills and technical know-how;

- the cost of BIM software and training of staff should be subsidize by the government and other approved authorities;

- appropriate government policies and guidelines that support BIM implementation should be in place in developing countries as whole; and

- BIM concept should be incorporated into academic curricula of architecture, engineering, and construction related disciplines in higher education

The significance of this study cannot be over-emphasized due to BIM relevance to the construction stakeholders and researchers at large. For instance, the study findings would inform the decisions of the construction stakeholders to make some policy recommendations capable of positively influencing the full implementation of BIM in AEC firms. 


\section{References}

Abanda, F., Vidalakis, C., Oti, A. and Tah, J. (2015), "A critical analysis of building information modeling system used in construction projects", Advances in Engineering Software, pp.183-201.

Abubakar, M., Ibrahim, Y. M., Kado, D. and Bala, K. (2014), “Contractors perception of the factors affecting building information modeling adoption in the Nigerian construction industry", Computing in Civil and Building Engineering,pp.167-178.

Abdullahi, M. and Ibrahim, Y.M. (2016), "Building information modeling, paper presented at 3-Day Workshop/Annual General Meeting of the Nigerian Institute of Quantity Surveyors, available at: http://niqs.org.ng/wp-content/uploads/2016/ (accessed 20 August 2018).

Akerele, A. O. and Etiene, M. (2016), “Assessment of the level of awareness and limitations on the use of building information modeling in Lagos State", International Journal of Scientific and Research Publications, Vol.6 No.2, pp.229-234.

Alufohai, A. (2012), “Adoption of building information modeling and Nigeria's quest for project cost management”, Journal of Nigerian institute of quantity surveyors, Vol.1 No.1, pp.610.

Amuda-Yusuf, G. (2018), "Critical success factors for building information modeling implementation", Construction Economics and Building, Vol.18 No.3, pp.55-73.

Aouad, G., Wu,S. and Lee, A. (2006), "nDimensional modeling technology: past, present, and future", Journal of Computing in Civil Engineering, Vol.20 No.3, pp. 151-153.

Aouad, G., Wu, S., Lee, A. and Onyewobi, T. (2014), Computer Aided Design Guide for Architecture, Engineering and Construction, Routledge, Taylor and Francis, London.

Arayici, Y., Khosrowshahi, F., Marshal Ponting, A. and Mihindu, S. (2009), "Towards implementation of building information modelling in the construction industry", 5th International Conference on Construction in the 21st Century (CITC-V), Collaboration and Integration in Engineering, Management and Technology, May 20-22, 2009, Istanbul, Turkey

Arayici, Y., Coates, P., Koskela, L., Kagioglou, M., Usher, C. and O'Reilly, K. (2011), "Technology adoption in the BIM implementation for lean architectural practice", Automation in Construction, Vol.20 No.2, pp.189-195.

Autodesk (2011), Realizing the benefits of BIM, autodesk building information modeling, available at: http://www.autodesk.com/bim (accessed 12 August 2018).

Autodesk (2012), How revit structure benefits the construction estimator, available at: http://www.augi.com/library/how-revitstructure- (Accessed 12 August 2018).

Azhar, S. (2011), "Building information modeling (BIM): trends, benefits, risks, and challenges for the AEC industry", Leadership and Management in Engineering, Vol. 11 No. 3, pp. 241-252.

Babatunde, S.O. (2015), "Developing public private partnership strategy for infrastructure delivery in Nigeria", Doctoral thesis, Northumbria University, UK. 
Babatunde, S.O. and Perera, S. (2017), "Barriers to bond financing for public-private partnership infrastructure projects in emerging markets: a case of Nigeria", Journal of Financial Management of Property and Construction, Vol. 22 No. 1, pp. 2-19.

Babatunde, S. O., Ekundayo, D., Babalola, O. and Jimoh, J. A. (2018), "Analysis of the drivers and benefits of BIM incorporation into quantity surveying profession: academia and students' perspectives", Journal of Engineering, Design and Technology, Vol.16 No.5, 750-766.

Babatunde, S. O. and Ekundayo, D. (2019), "Barriers to the incorporation of BIM into quantity surveying undergraduate curriculum in the Nigeria universities", Journal of Engineering, Design and Technology, Vol.17 No.3, pp.629-648.

Badu, E., Edwards, D.J., Owusu-Manu, D. and Brown, D.M. (2012), "Barriers to the implementation of innovative financing (IF) of infrastructure", Journal of Financial Management of Property and Construction, Vol. 17 No. 3, pp. 253-273.

Bernstein P. G. and Pittman J. H. (2014), Barriers to the adoption of building information modeling in the building industry, Autodesk Building Solutions White Paper.

BIPS (2012), The Danish BIM guidelines, available at: http://iug.buildingsmart.org/resources/process-room-workshop-21-march

(accessed 12 August 2018).

Brown, J.D. (2009), "Choosing the right type of rotation in PCA and EFA", JALT Testing and Evaluation SIG Newslettter, Vol. 13 No. 3, pp. 20-25.

Building Cost Information Service (BCIS) (2011), Building Information Modelling Survey Report, Royal Institution of Chartered Surveyors (RICS), UK.

BIM Industry working Group (2011), A report for the government construction client group building information modeling, working party strategy paper, available at: http://www.bimtaskgroup.org/wp-content/uploads/2012/03/BISBIM-strategy-Report.pdf. (accessed 12 August 2018).

BuildSmart (2013),"BIM-the way forward building \& construction, A Construction Productivity Magazine, Vol.13 No.18, pp.1-3.

Cabinet Office (2012), Government construction strategy, one year on report and action plan update, available at: http://www.cabinetoffice.gov.uk/resourcelibrary/governmentconstruction-strategy (accessed 12 August 2018).

Chao-Duivis, M. (2009), Legal implications of working with BIM, The Hague, March 2009. P. 44.

Christensen, S., McNamara, J. and O'Shea, K. (2007), "Legal and contracting issues in electronic project administration in the construction industry", Structural Survey, Vol.25 No.3/4, $191-203$.

China Construction Industry Association (CCIA) (2013), Research of BIM application in construction firms (1), China Architecture and Building Press, Beijing. 
Coates, P., Arayici, Y., Koskela, L. and Usher, C. (2010), The changing perception in the artefacts used in the design practice through BIM adoption in: CIB 2010, University of Salford, UK.

Crotty, R. (2012), The impact of building information modelling transforming construction, Taylor and Francis, London, UK.

Eadie, R., Odeyinka, H., Browne, M., McKeown, C. and McNiff, S. (2013), BIM implementation throughout the UK construction project lifecycle: an analysis", Automation in Construction Vol.36, pp.145-151.

Eastman, C., Teicholz, P., Sacks, R. and Liston, K. (2008) BIM Handbook: A Guide to Building Information Modeling for Owners, Managers, Designers, Engineers, and Contractors.2008. 21

Efficiency and Reform Group (2011), Government Construction Strategy, Cabinet Office, London, UK.

Enegbuma, W.I., Dodo, Y.A. and Ali, K.N. (2014), "Building information modelling penetration factors in Malaysia”, International Journal of Advances in Applied Sciences, Vol.3 No.1, pp.47-56.

Ezeokoli, F. O., Okoye, P. U. and Nkeleme, E. (2016), "Factors affecting the adaptability of building information modeling for construction projects in Anambra state Nigeria.

Journal of Scientific Research \& Reports, Vol.11 No.5, pp.1-10.

Fellows, R. R. and Liu, A. (2008) Research Methods for Construction, Wiley-Blackwell Science, London.

Gardezi, S.S., Shafiq, N., Faris, M. and Khamidi, B. (2014), "Prospects of building information modeling in Malaysian construction industry as conflict resolution tool", Journal of Energy Technologies and Policy, Vol.3 No.11, pp.346-350.

Giel, B., Issa, R.R.A. and Olbina, S. (2010), Return on investment analysis of building information modelling in Construction. Nottingham, Nottingham University Press.

Hong Kong Construction Industry Council. (2013), "Final draft report of the roadmap for BIM strategic implementation in Hong Kong's construction industry", available at: http://www.hkcic.org (accessed 12 August, 2018).

Hair, J.F., Black, W.C., Babin, B.J. and Anderson, R.E. (2010), Multivariate Data Analysis: A Global Perspective, Pearson, Upper Saddle River, NJ, London.

Hamma-adama, M., Salman, H. S. and Kouider, T. (2017a), "Diffusion of innovations: the status of building information modeling uptake in Nigeria", Journal of Scientific

Research and Reports, Vol.17 No.4, pp.1-12.

Hamma-adama, M., Salman, H. S. and Kouider, T. (2017b) BIM adoption in Nigeria: state of building information modeling adoption in Nigeria, The ARCOM 2018 Conference, Belfast, UK, 3-5 ${ }^{\text {th }}$ September, 2018.

Hergunsel, M.F. (2011) Benefits of building information modeling for construction managers and BIM based scheduling, published M.Sc. Thesis, Worcester Polytechnic Institute, Worcester. 
Hosseini, M. R., Azari, E., Tivendale, L. and Chileshe N. (2015), "Barriers to adoption of building information modelingin Iran: preliminary results", available at: http://researchoutputs.unisa.edu.au/11541.2/117470 (accessed 12 August 2018).

Ibrahim, S. and Birshir I. (2012), "Review of using building information modeling in Nigerian construction industry", Journal of Environmental Sciences and Policy Evaluation, Vol.2 No.2, pp.52-62.

Ikediashi, D. and Joseph, U. (2016), "Adoption of BIM technologies for facilities management roles in Nigeria: an empirical investigation", Paper presented at the ICCREM.

Isa, M. (2015), Developing a roadmap for the implementation of building information modeling (BIM) in the Nigerian construction industry, MSc. Thesis, Ahmadu Bello University, Zaria, Nigeria.

Jordani, D. (2008), BIM: a healthy disruption to a fragmented and broken process, Journal of Building Information Modelling, pp.24-26.

K'Akumu, O.A., Jones, B. and Yang, J. (2013), "Factor analysis of the market environment for artisanal dimension stone in Nairobi, Kenya", Journal of Construction in Developing Countries, Vol. 18 No. 2, pp. 15-32.

Kjartansdóttir, I. (2011). BIM adoption in Iceland and its relation to lean construction, master of science thesis, School of Science and Engineering at Reykjavík University, Reykjavík.

Kerosuoa, H., Miettinena, R., Paavolaa, S., Mäkia, T. and Korpelaa, J. (2015), "Challenges of the expansive use of building information modeling in construction projects. Production", Vol.25 No.2, pp.289-297.

Kline, P. (2002), An Easy Guide to Factor Analysis, Routledge, London.

Kori, S.A. and Arto, K. (2015), Toward adoption of BIM in the Nigerian AEC industry; context framing, data collecting and paradigm for interpretation. Paper presented at the 9th BIM Academic Symposium \& Job Task Analysis Review, NIBS-Washington DC, USA, available at: http://livrepository.liverpool.ac.uk/id/eprint/2007727 (Accessed 12 August 2018).

Latiffi, A.A., Mohd, S., Kasim, N. and Fathi, S.M. (2013), "Building information modelling application in Malaysian construction industry", International Journal of Construction Engineering and Management. Vol.2 No.4A, pp.1-6.

Lee, G., Harrison, K. and Won, J. (2012), "Economic impact of BIM-assisted design validation", Automation in Construction, Vol.22 No.1, pp.577-586.

Lee, S., Kim, K. and Yu, J. (2014), "BIM and ontology-based approach for building cost estimation", Automation in Construction, Vol. 41, pp.96-105.

Liu S., Xie B., Tivendal, L., and Liu C. (2015), "Critical barriers to BIM implementation in the AEC industry", International Journal of Marketing Studies, Vol.7 No.6, pp.162-171.

Lu, W., Chen, K., Zetkulic, A. and Liang, C. (2018), "Measuring building information modelling maturity: a Hong Kong case study", International Journal of Construction Management, pp.1-13.

Matarneh, R.T. and Hamed, S.A. (2017), "Exploring the adoption of building information 
modeling in the Jordanian construction industry", available at: https://doi.org/10.4172/2168-9717.1000189 (accessed 12 August, 2018).

McGraw-Hill. (2008), Building information modeling: transforming design and construction to achieve greater industry productivity, Bedford, SmartMarket Report, Research and Analysis, Bedford, MA.

McGraw-Hill. (2009), The business value of BIM: getting building information modeling to the bottom line, Bedford, SmartMarket Report, Research and Analysis, Bedford, MA.

McGraw-Hill. (2014), The business value of BIM for construction in global markets: how contractors around the world are driving innovation with building information modeling, SmartMarket Report, Research and Analysis, Bedford, MA.

Memon, A.H, Rahman, I. A, Memon I. and Azman, N. A. (2014), "BIM in Malaysian construction industry: status, advantages, barriers and strategies to enhance the implementation level", Research Journal of Applied Sciences, Engineering and Technology, Vol.8 No.5, pp.606-614.

Migilinskas, D., Popov, V., Juocevicius, V. and Ustinovichinus, L. (2013), "The benefits, obstacles and problems of practical BIM implementation, Procedia Engineering, Vol.57, pp.767-774.

Mihindu, S. and Arayici, Y. (2008) "Digital construction through BIM systems will drive thereengineering of construction business practices”, Proceedings of the InternationalConference Visualisation, IEEE Computer Society, Los Alamitos, CA. 9-11 July2008, pp.29-34.

Obiegbu, M. E, and Ezeokoli, F. O. (2014), "Building information modeling, a panacea for timely project delivery, being a paper delivered at River State quantity surveyor's week holding at The Arena Event Centre, Tombia Street, Port Harcourt, Nigeria.

Oduyemi, O.,Michael, I.O. and Fajana, S. O. (2017), “The application and barriers of BIM in sustainable building design”, Journal of Facilities Management, Vol.15 No.1, pp.15-34.

Olapade, D. T. and Ekemode, B. G. (2018), "Awareness and utilisation of building information modeling for facility management (FM) in a developing economy", Journal of Facilities Management, Vol.16 No.4, pp.387-395

Olugboyega, O. and Aina, O. (2016), "Analysis of building information modelling usage indices and facilitators in the Nigerian construction industry", Journal of Logistics, Information and Service Sciences. Vol.3 No.2, pp.1-36.

Oluwole, A. (2011), "A preliminary review on the legal implications of BIM and model ownership, Journal of Information Technology in Construction (ITcon), Vol.16, pp.687696.

Onungwa, I. O., Uduma-Olugu, N. and Igwe, J.M. (2017) "Building information modeling as a construction management tool in Nigeria", WIT Transactions on the Built Environment, Vol.169, pp.25-33.

Pallant, J. (2007), SPSS Survival Manual: A Step By Step Guide to Data Analysis Using SPSS for Windows, Open University Press, Berkshire. 
Pallant, J. (2010). SPSS Survival Manual: A Step to Step Guide to Data Analysis Using SPSS for Windows, Open University Press

Poole, K. (2014), "BIM initiatives by Hong Kong construction industry council”, available at: http://www.cic.hk/files/page/51/HKCIC_FinalReport_PublicSector 201511.pdf (accessed 20 December 2019).

Race, S. (2012). BIM Demystified, RIBA Publishing, UK.

Saleh, M .A. D. (2015), Barriers and driving factors for implementing building information modeling in Libya, Master's thesis, Eastern Mediterranean University (EMU)DoguAkdenizUniversitesi (DAU).

Saxon, R.G. (2013), Growth through BIM. Construction Industries Council, London, England.

Smith, D and Tardif, M (2009), Building Information Modeling: A Strategic Implementation Guide for Architects, Engineers, Constructors, and Real Estate Asset Managers, John Wiley \& Sons, Inc, Hoboken, New Jersey.

Singh, I. (2017), "BIM adoption and implementation around the world: initiatives by major nations", available at: http://www.geospatialworld.net/blogs/bim-adoption-aroundthe-world/(accessed 12 August 2018).

Thompson, D. and Miner, R., (2010), "Building information modeling: contractual risks are changing with technology", available at: http://aepronet.infinityit.com/Guest $\% 20$ Essays/GE\%20\%202006_09\%20\%20Building\%2 (accessed 12 August 2018).

Tuuli, M. M. and Rowlinson, S. (2009), Empowerment in project teams: a multilevel examination of the job performance implications, Construction Management and Economics, Vol.27, pp.473-498.

Ugochukwu, S.C., Akabogu, S.C. and Okolie, K.C. (2015), "Status and perceptions of the application of building information modeling for improved building projects delivery in Nigeria", American Journal of Engineering Research, Vol.4 No.11, pp.176-182.

UK BIM Strategy Report (2012) Industrial Strategy: Building Information Modeling, Industrial Strategy: Government and Industry in Partnership, Her Majesty Government, London.

Wang, C., Adetola, S.H. and Abdul-Rahman, H. (2015), “Assessment of BIM implementation among MEP firms in Nigeria", International Journal of Advances in Applied Sciences, Vol.4 No.3,pp.73-81.

Watson, A. (2010), BIM - A driver for change, Proceedings of the International Conference on Computing in Civil and Building Engineering, (Ed. Tizani, W.), University of Nottingham, available

at: http://www.engineering.nottingham.ac.uk/icccbe/proceedings/pdf/pf69.pdf (Accessed 12August 2018).

Wong, A., Wong, F. and Nadeem, A. (2009), Comparative roles of major stakeholders for the implementation of BIM in various countries, Hong Kong Polytechnic University, Hong Kong. 
Young, N.W, Jones, S.A. and Bernstein, H.M. (2008) Building information modeling transforming design and construction to achieve greater industry productivity. McGraw-Hill. New York.

Yan, H. and Damian P. (2008), "Benefits and barriers of building information modeling", available at:

http://homepages.lboro.ac.uk/ cvpd2/PDFs/294_Benefits\%20and\%20Barriers\%2 0of\%20Building\%20Information\%20Modelling.pdf (Accessed 12 August 2018).

Zahrizan Z., Ali, N.M., Haron, A.T., Marshall-Ponting, A. and Hamid Z.A. (2013), "Exploring the adoption of building information modeling in the Malaysian construction industry: a qualitative approach", International Journal of Research in Engineering and Technology, Vol.2 No.8, pp.384-395.

Zikmund, W. G. (2003) Business Research Methods, Thomson Learning, USA.

Zuhairi, A.H., Marshall-Ponting, A., Ahmad, T.H., Nasly, M.A. and Zahrizan, Z. (2014), "Exploring the barriers and driving factors in implementing building information modelling in the Malaysian construction industry - a preliminary study. The Institution of Engineer, Malaysia Journal,Vol.75 No.1, pp. 1-10. 